\title{
Pyrgeometer Calibration for DOE-Atmospheric System Research program using NREL Method
}

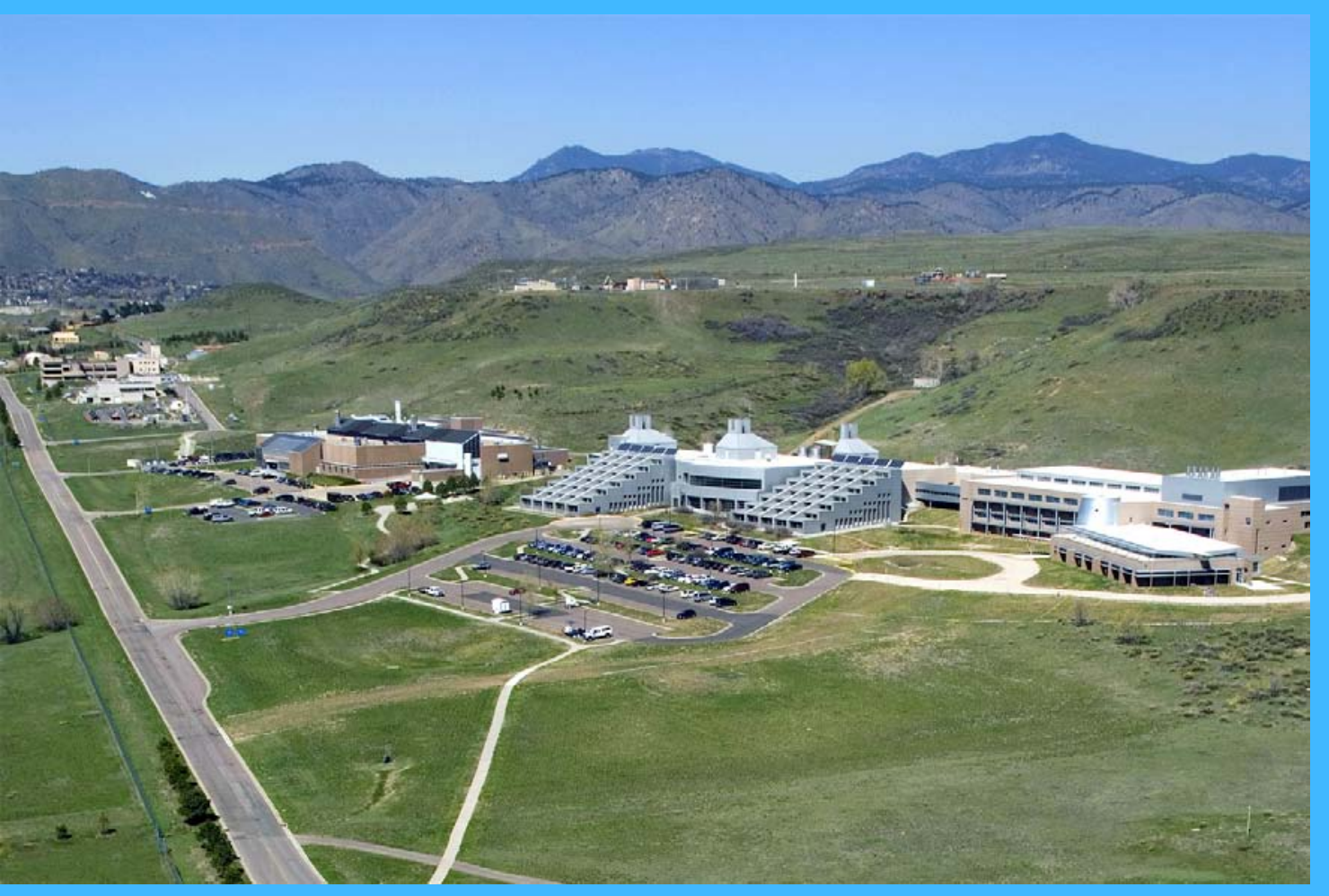

Science Team Meeting

Ibrahim Reda

Tom Stoffel

Date 3/15/2010

NREL/PR-3B0-47756 


\section{Overview to address some ECR comments}

Thermocouple/thermopile

Pyrgeometer thermodynamics

NREL \& PMOD equations

NREL calibration method

Conclusion. 


\section{Effect of increased junctions on thermopile}

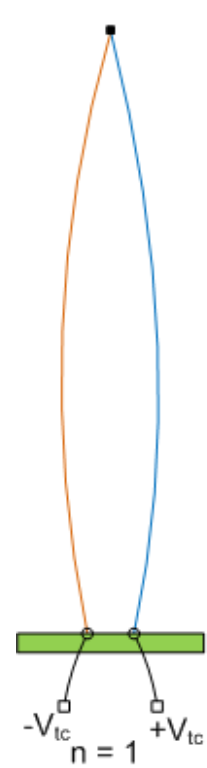

Temperature of Receiving Junctions $=\mathrm{T}_{\mathrm{r}}$

Isothermal block

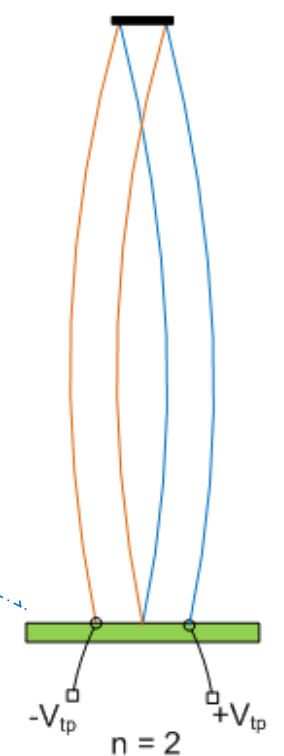

Isothermal block

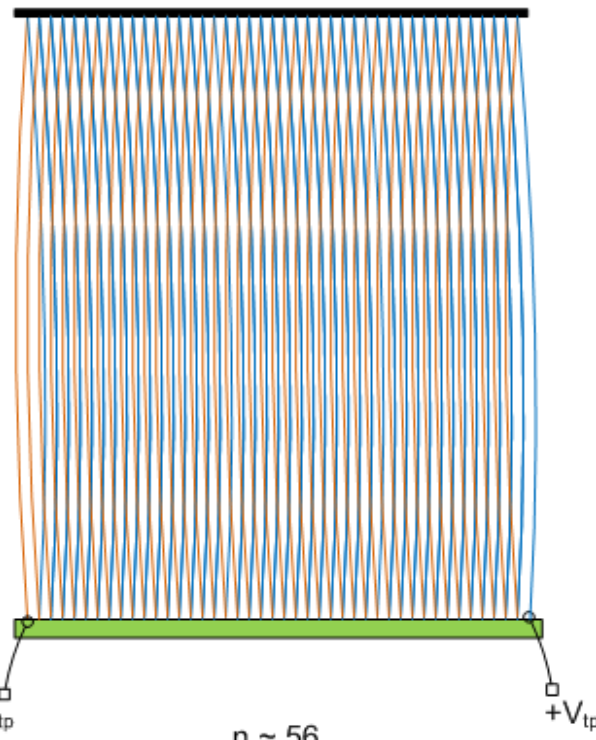

Temperature of Reference Junctions $=\mathrm{T}_{\text {ref }}$

$$
V_{\text {tp }}=\text { n.s.e }\left(T_{r}-T_{\text {ref }}\right)
$$

where,

$\mathrm{n}=$ number of junctions

$s=$ Seebeck coefficient

$\mathrm{e}=$ thermopile efficiency. $\mathrm{e}=1$ for $\mathrm{n}=1,2$, or small number

$\mathrm{n} \uparrow$ to increase signal/noise ratio, thermal conductivity between receiving\&reference junctions $\uparrow, T_{\text {ref }}$ effect on $T_{r} \uparrow$, therefore $\mathbf{e} \neq 1$

If $\mathbf{n}$ is not optimum $\rightarrow \mathbf{V}_{\text {tp }} \downarrow$, $\mathbf{n}$ too large $\mathbf{V}_{\text {tp }} \sim$ zero volt 


\section{Effect of increased thermal conductivity on PIRs}

Temperature of Receiving Junctions $=\mathrm{T}_{\mathrm{r}}$

Not to scale

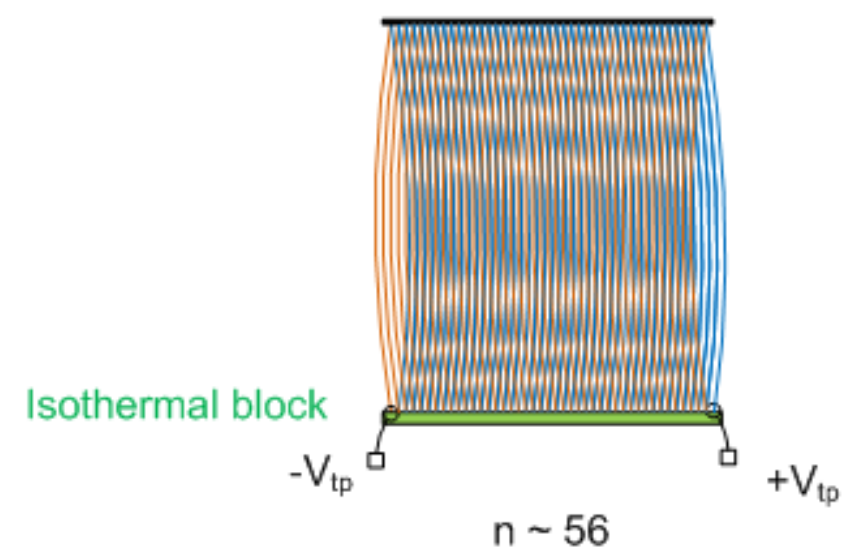

Temperature of Reference Junctions $=\mathrm{T}_{\text {case }}$

$V_{t p}=$ n.s.e $\left(T_{r}-T_{\text {case }}\right)$

where $\mathrm{e}=0.65$ for PIRs, measured by John Hickey for PIRs with $\mathrm{n} \sim 56$ junctions and Seebeck coefficient $\sim 39 \mu \mathrm{V} / \mathrm{K}$, reported in:

Reda et al., (2002). Pyrgeometer Calibration at the National Renewable Energy Laboratory (NREL). Journal of Atmospheric and Solar-Terrestrial Physics. Vol. 64(15), 2002; pp. 1623-1629.

therefore,

$$
T_{r}=T_{\text {case }}+0.0007044 V_{t p}
$$




\section{Simplified pyrgeometer thermodynamics}

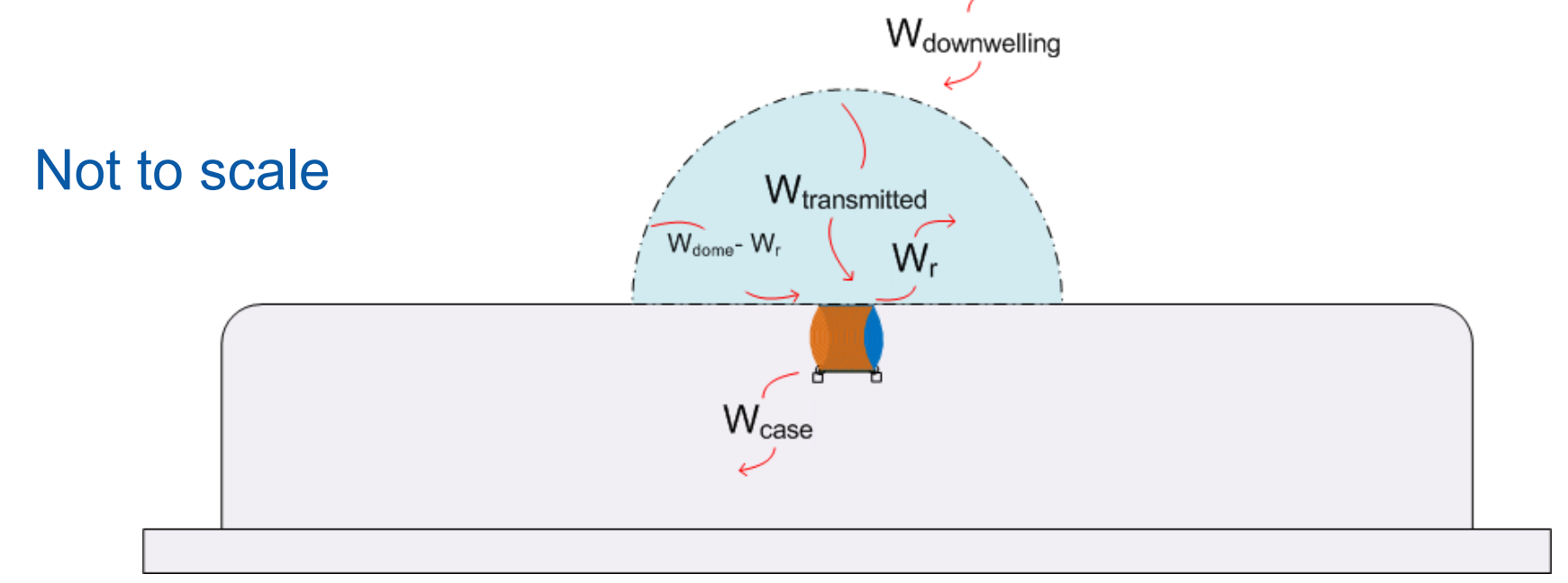

- Net Irradiance $=\mathrm{W}_{\text {net }}=\mathrm{K}_{1}{ }^{\prime} \cdot \mathrm{V}_{\mathrm{tp}}$

$$
=\mathrm{W}_{\text {incoming }}-\mathrm{W}_{\text {outgoing }}=\mathrm{W}_{\text {transmitted }}+\mathrm{K}_{3}{ }^{\prime} \cdot\left(\mathrm{W}_{\text {dome }}-\mathrm{W}_{\mathrm{r}}\right)-\mathrm{K}_{2}{ }^{\prime} \cdot \mathrm{W}_{\mathrm{r}}
$$

where $W_{\text {transmitted }}=\tau$. $W_{\text {downwelling }}$, and $\tau=$ Dome+Filter transmittance .. assumed to be constant

Other equations are based on assumptions: $\mathrm{e}=1$ and $\mathrm{W}_{\text {outgoing }}=\mathrm{W}_{\text {case }}$ instead of $\mathrm{W}_{\mathrm{r}}$ !?!

- Arrange the above equation and Re-name constants, therefore,

$$
\mathrm{W}_{\text {downwelling }}=\mathrm{K}_{1} \cdot \mathrm{V}_{\mathrm{tp}}+\mathrm{K}_{2} \cdot \mathrm{W}_{\mathrm{r}}-\mathrm{K}_{3} \cdot\left(\mathrm{W}_{\text {dome }}-\mathrm{W}_{\mathrm{r}}\right)
$$

This is NREL's equation without $K_{0}$, Reda et al., (2002). Pyrgeometer Calibration at the National Renewable Energy Laboratory (NREL). Journal of Atmospheric and Solar-Terrestrial Physics. Vol. 64(15), 2002; pp. 1623-1629.

$\mathrm{K}_{0}$ is reserved for troubleshooting regressions \& blackbody calibrations only 


\section{Comparing NREL and PMOD equations}

\section{NREL Equation:}

$$
W_{\text {downwelling }}=K_{1} \cdot V_{t p}+K_{2} \cdot W_{r}-K_{3}\left(W_{\text {dome }}-W_{r}\right)
$$

\section{Expansion of NREL Equation to compare with PMOD equation:}

1. $T_{r}=T_{\text {case }}+0.0007044 V_{\text {tp }} \ldots$. for PIRs

2. $\mathrm{W}_{\text {downwelling }}=\mathrm{K}_{1} \cdot \mathrm{V}_{\mathrm{tp}}+\mathrm{K}_{2} \cdot \sigma\left(\mathrm{T}_{\text {case }}+0.0007044 \mathrm{~V}_{\mathrm{tp}}\right)^{4}-\mathrm{K}_{3}\left[\mathrm{~W}_{\text {dome }}-\sigma\left(\mathrm{T}_{\text {case }}+0.0007044 \mathrm{~V}_{\mathrm{tp}}\right)^{4}\right]$

Expand $\left(T_{\text {case }}+0.0007044 V_{t p}\right)^{4}$ using $(a+b)^{4}=a^{4}+4 a^{3} b+6 a^{2} b^{2}+4 a b^{3}+b^{4}$

3. Arrange terms and re-name coefficients,

$$
\begin{gathered}
\mathrm{W}_{\text {downwelling }}=\mathrm{K}_{1} \cdot \mathrm{V}_{\mathrm{tp}}+\mathrm{k}_{1}^{\prime} \cdot \mathrm{T}_{\text {case }}{ }^{3} \cdot \mathrm{V}_{\mathrm{tp}}+\mathrm{k}_{2} \cdot \mathrm{W}_{\text {case }}-\mathrm{k}_{3}\left(\mathrm{~W}_{\text {dome }}-\mathrm{W}_{\text {case }}\right)+\mathrm{k}_{4} \cdot \mathrm{T}_{\text {case }}{ }^{2} \cdot \mathrm{V}_{\mathrm{tp}}{ }^{2}+ \\
\mathrm{k}_{5} \cdot \mathrm{T}_{\text {case }} \cdot \mathrm{V}_{\mathrm{tp}}{ }^{3}+\mathrm{k}_{6} \cdot \mathrm{V}_{\mathrm{tp}}{ }^{4}
\end{gathered}
$$

\section{PMOD Equation:}

$$
\begin{aligned}
\mathrm{W}_{\text {downwelling }} & =\mathrm{V}_{\mathrm{tp}}\left(1+\mathrm{k}_{1} \cdot \sigma \cdot \mathrm{T}_{\text {case }}{ }^{3}\right) / \mathrm{c}+\mathrm{k}_{2} \cdot \mathrm{W}_{\text {case }}-\mathrm{k}_{3}\left(\mathrm{~W}_{\text {dome }}-\mathrm{W}_{\text {case }}\right) \\
& =\mathrm{K}_{1} \cdot \mathrm{V}_{\mathrm{tp}}+\mathrm{k}_{1}^{\prime} \cdot \mathrm{T}_{\text {case }}{ }^{3} \cdot \mathrm{V}_{\mathrm{tp}}+\mathrm{k}_{2} \cdot \mathrm{W}_{\text {case }}-\mathrm{k}_{3}\left(\mathrm{~W}_{\text {dome }}-\mathrm{W}_{\text {case }}\right)
\end{aligned}
$$

! PMOD equation $=$ NREL equation without $k_{4}, k_{5}$, and $k_{6}$ terms !

From many comparisons, $\mathrm{U}_{95}$ using NREL or PMOD equation $=(1$ to 3$) \mathrm{W} / \mathrm{m}^{2}$ w.r.t. WISG 


\section{NREL Calibration Procedure}

Procedure is developed after many comparisons/validations with PMOD/NOAA Calibration is performed outdoor using a group of reference pyrgeometers with traceability to consensus reference, WISG

Recommended Measurement Equation:

\section{Process:}

$\mathrm{W}_{\text {downwelling }}=\mathrm{K}_{1} \cdot \mathrm{V}_{\mathrm{tp}}+\mathrm{K}_{2} \cdot \mathrm{W}_{\mathrm{r}}-\mathrm{K}_{3}\left(\mathrm{~W}_{\text {dome }}-\mathrm{W}_{\mathrm{r}}\right)$

1. $\quad \mathrm{V}=$ minimum negative magnitude (Cloudy sky), adjust $\mathrm{K}_{2}$ to minimize the difference between pyrgeometer under test (PUT) irradiance and reference irradiance

2. $\quad \mathrm{V}=$ maximum negative magnitude (Clear sky), adjust $\mathrm{K}_{1}$ to minimize the difference between the PUT irradiance and reference irradiance

3. Adjust $\mathrm{K}_{3}$ to minimize the scatter of the differences between PUT irradiance and reference irradiance.

Future software development might include/evaluate regression, with uniform sets of data!!, to calculate the calibration coefficients 


\section{NREL Calibration Method Validation}

\section{At least 40 pyrgeometers were calibrated using NREL method with uncertainty $U_{95}<3 \mathrm{~W} / \mathrm{m}^{2}$ with respect to WISG, for all sky conditions, e.g.}

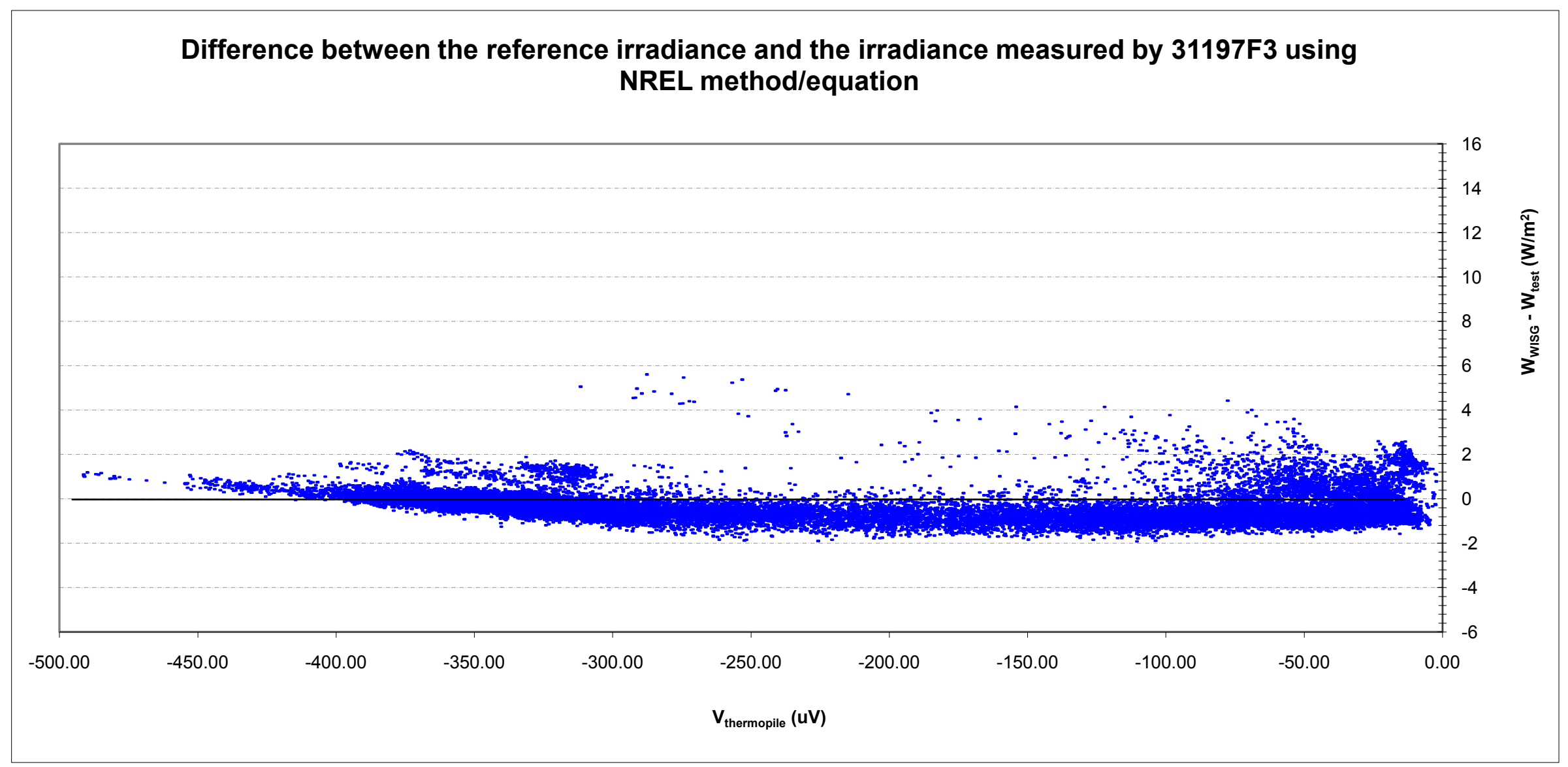




\section{Conclusions}

NREL method achieves uncertainty of $<3 \mathrm{~W} / \mathrm{m}^{2}$ for all sky conditions

NREL equation accounts for the pyrgeometer thermodynamics

Since $T_{r}=T_{\text {case }}+0.0007044 V_{t p}$, and response time of thermopile is faster than case temperature response, therefore, NREL equation reduces response time of measuring $\mathrm{W}_{\text {downwelling }} . .$. needed for fast changes in sky conditions

At present, with the instruments/data-acquisition limitations, all equations might achieve $U_{95}=(1$ to 3$) \mathrm{W} / \mathrm{m}^{2}$ w.r.t. WISG

In the future, when $U_{95}$ of measuring instruments and consensus reference is reduced, NREL equation might be a good candidate when uncertainty of fractions of $\mathrm{W} / \mathrm{m}^{2}$ is needed

Manufacturers specifications to include thermopile efficiency, e, for accurate $\mathrm{K}_{2}$ and $\mathrm{K}_{3}$ derivation. 